\title{
Piloting a Use of Graphic Tablets to Support Students Drawing within a Secondary School in Iceland
}

\author{
Gisli Thorsteinsson \\ University of Iceland, \\ cdt@hi.is
}

\begin{abstract}
This paper reports a research study, undertaken during the autumn of 2011, within a secondary school in Iceland. The author tried to gain experience of using digital or graphic tablets for drawing, in a school context. The research study was based on observations within a complex social/educational context, in a school classroom. Data was gathered in a naturalistic way and analysed, according to the principles of the grounded theory of Glaser and Strauss (1967). The aim of study was to develop an understanding of the value and possibilities for using more advanced drawing technologies within a school based education. The researcher based his research around the following questions: 1 . What are the differences between conventional drawing and drawing with graphic tablets? 2. What is the value of using digital tablets for drawing, within the context of secondary school education? 3. How can the students' abilities to draw using digital input devices be improved?
\end{abstract}

Keywords: Graphic tablets, drawing, digital output devices, secondary school, design, research.

\section{Introduction}

Using graphic tablets technology enables students to develop drawings and descriptions of their solutions supported by CAD and digital output devices. A study was undertaken in an Icelandic secondary school, using graphic tablets to facilitate students design work within the context of a classroom. The aim of the study was to gain understanding of the meaning of using digital drawing in the context of images developed by students during their work. The produced data was qualitative and analysis based on grounded theory principles and an interpretive paradigm.

Three data instruments were used to enable triangulation: observation, students' drawings from tests in the classroom, interviews with the teacher, interviews with individual students, screen captured videos and video recordings in the classroom. Using remote observation software allowed the collation of a rich record of actual computer work activity in its natural work setting. A qualitative and inductive methodology, developed by Glaser and Strauss (1967), was used to analyse the data. Moreover, the data analysis was supported by postgraduate students at Loughborough University.

The rapid rise of computers and digital output devices has seen the introduction of novel forms of education and learning supports (Page, 2011). Such learning comes in a range of forms and is therefore difficult to characterise. However, it is important to examine the way new technology is used in school and its value for learning as it offers many possibilities and will replace the idea of teaching as a form of information provided by an instructor during lectures and printed course materials (Page, Thorsteinsson, Niculescu, 2009; McInnerney 2002).

The study examined the possibilities of using digital output devices for drawing. The process attempted to understand the value of conventional method using a simple pencil and drawing tables. The author observed the impact of students' drawing on their drawings and designs.

A drawing tablet is a digital input device that enables a designer to hand-draw images, alike to the way someone draws an image with a pencil and paper. Such tablets may also be used to capture figures or handwritten signatures. It can, furthermore, be utilised to trace a sketch from a paper which is taped to a surface. Capturing figures in this way, both by tracing or entering the corners of linear poly-lines or forms are named digitizing.

During the study, use of graphic tablets was identified as an interesting part of students drawing inside the classroom. It affected both the time it took to generate solutions and the qualities of the work. Furthermore, it concerned the students' ability to express their thoughts and communicate their ideas.

The author firstly introduces the pilot study and reviews the literature. Then, he discusses the research design, the undertakings of the research study and the findings. Finally, he analyses the outcome and draws his conclusions.

\section{Computer Input Devices for Drawing}

A drawing tablet (also named pen pad or digitizer) comprises a flat surface upon which 
the user can "draw" or trace a figure implementing an attached stylus, a pen-like sketching device. The figure usually does not upraise on the tablet but on a computer monitor. Some tablets, nevertheless, function as a secondary computer screen that enables the designer to interact with the images by using the stylus. Furthermore, many tablets are designed as a universal replacement for a mouse as the main pointing and navigation tool for desktop computers.

The oldest electronic hand-script tablet was the Telautograph. It was invented by Elisha Gray and patented on July 31, 1888 (Britanica, 2012). Elisha's patent stated that the telautograph would allow "one to transmit his own handwriting to a distant point over a twowire circuit." subsequently, triangulated by a series of microphones (Fischer, 2001). This design was rather multifaceted and costly, and the sensors were often disturbed by outer noise.

Digitizers became popular in the mid-1970s and early 1980s when the ID (Intelligent Digitizer) and BitPad were manufactured by the Summagraphics Corp(Coppock \& Rhind, 1991). These digitizers were implemented as the digital input device for many pieces of Computer Aided Design software such as AutoCAD.

\section{The Tablets Used for the Study}

The initial digital tablet was basically a "Trust" PC Note Taker. The pen was wireless but not with an ink. Therefore the students had to watch the computer screen during their work as they were not able to see the drawing at the

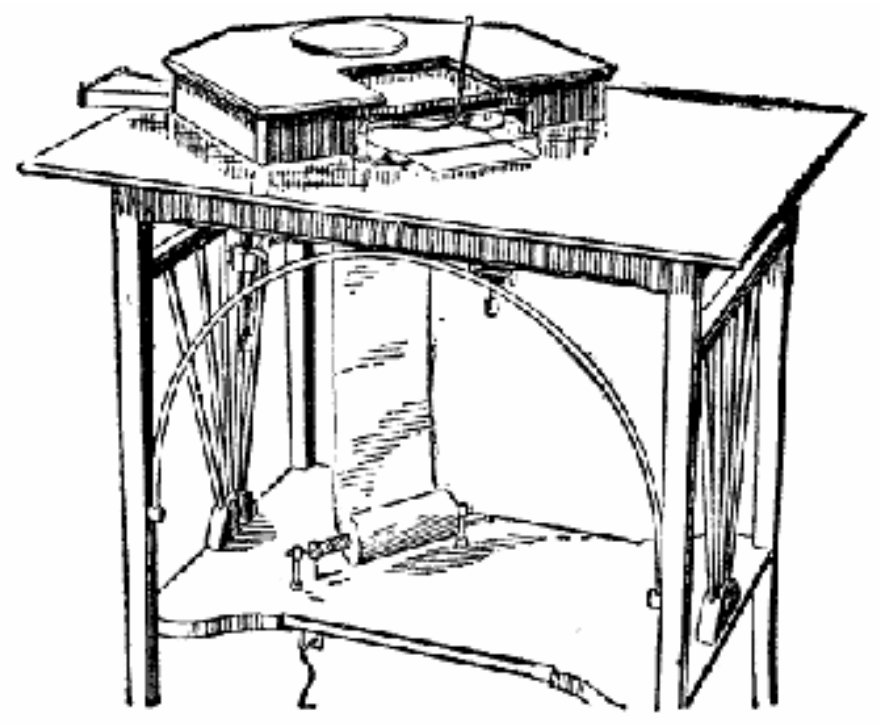

Figure 1. An early telautograph

The initial drawing tablet that looked like contemporary tablets was the Stylator in 1957. Stylator was implemented for hand-writing recognition via a computer (Dimond, 1957). Another well-known tablet at this time was the Rand Tablet that was introduced in 1964 (Davis, 1964). The Rand Tablet is also known as the Grafacon (for Graphic Converter). The Rand Tablet was based on a grid of wires under the surface of the pad that coded horizontal and vertical coordinates as a magnetic signal.

Later graphics tablets were commonly known as acoustic tablets. They used a stylus that produced clicks with a spark plug. In order to locate the pen in space clicks were, tablet. This tablet was compatible with most CADs and used in this research with the software Paint that is part of the Microsoft operating system.

The "Pegasus" tablet was an electronic pen that captured drawings and transferred them via the USB-connected receiver to a PC. This was based on specific software and not usable with other software applications. The students did, however, not have to look at the computer screen at the same time they drew like with the initial pens as the Pegasus pens were ink based and they could also see their drawings appear on the paper. 

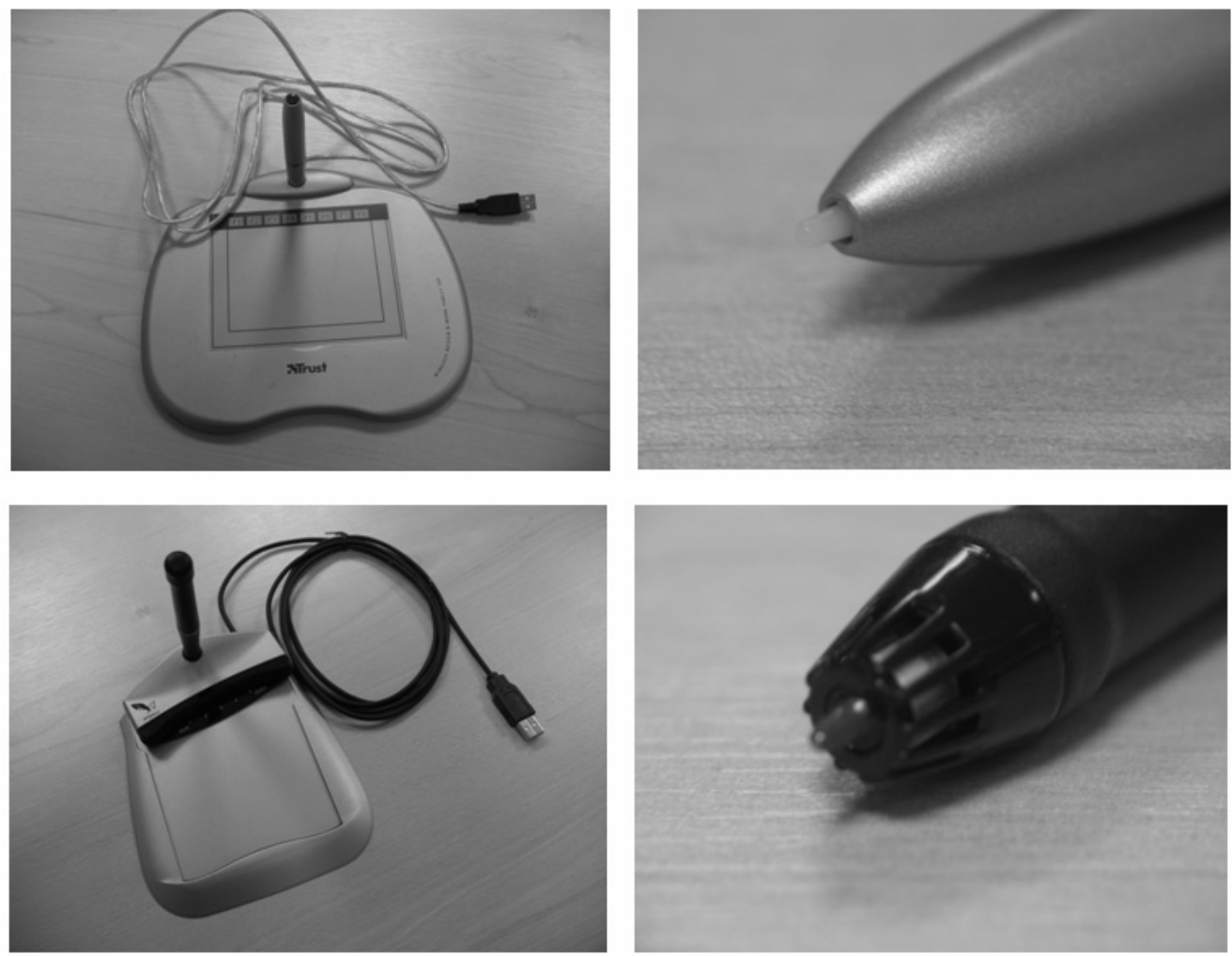

Figure 2. The initial digital pen tablet (above) and the Pegasus pen tablet (below).
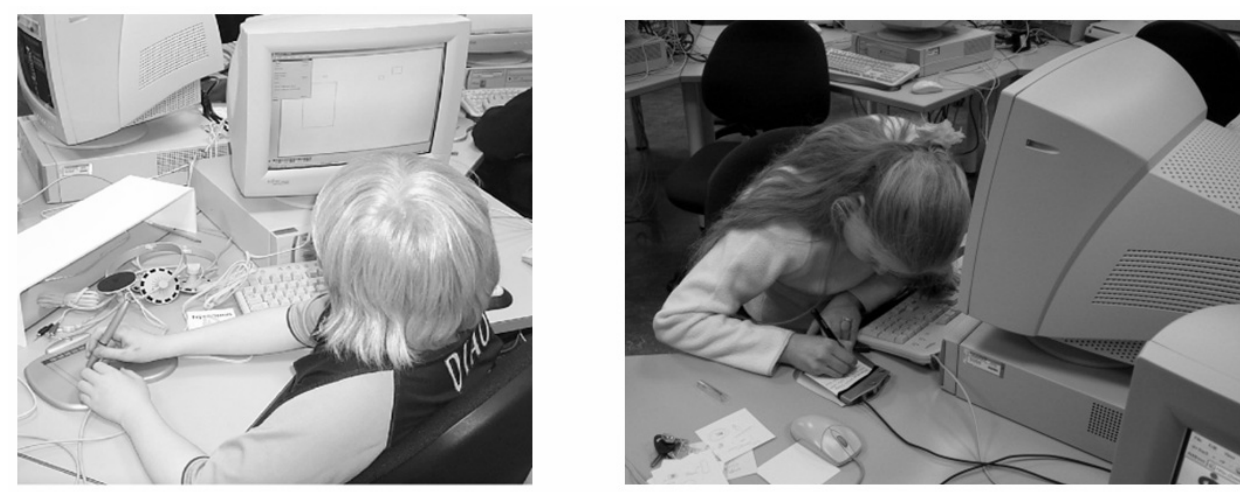

Figure 3. The student on the left is using the initial digital pen tablet and the student on the right is using the Pegasus pen tablets.

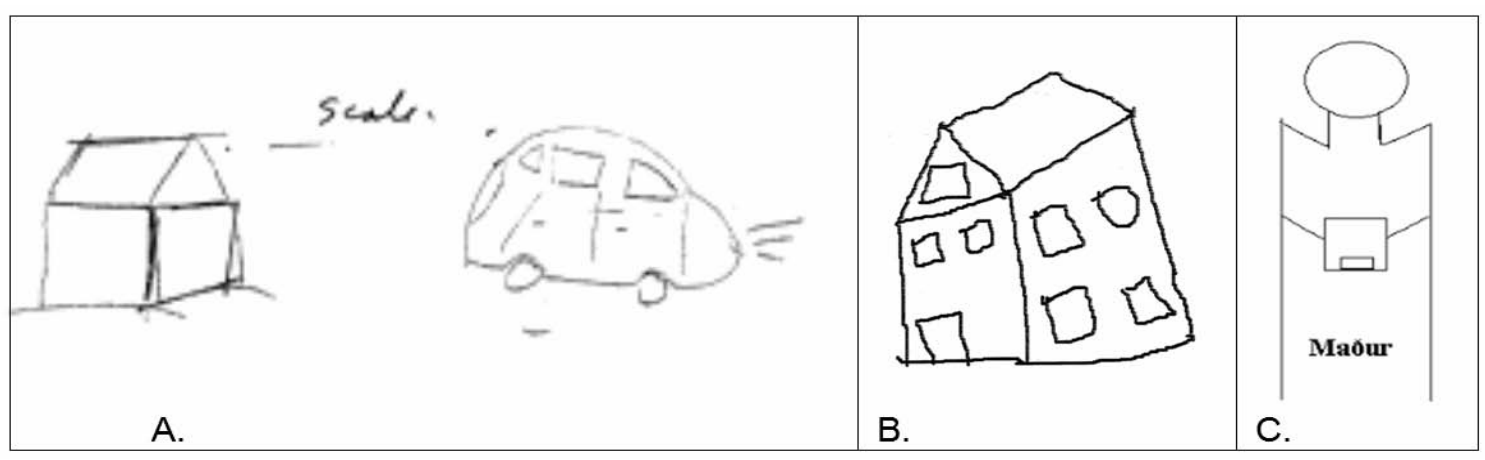

Figure 4. Shows examples of students' drawings. A. is a drawing made with a pencil, B. was made with the initial tablet and C. was made with the Pegasus digital pen tablets. 


\section{Research Design}

The aim of study was to gain an experience and understanding of using more advanced drawing technologies within a school based design education unit.

The objectives were to:

1. Observe students drawing within the classroom.

2. Gain experience of using digital output devices.

The researcher based his research around the following questions:

1. What are the differences between conventional drawing and drawing with graphic tablets?

2. What is the value of using digital tablets for drawing, within the context of secondary school education?

3. How can the students' abilities to draw using digital input devices be improved?

Ten students, five boys and five girls from class seven, took part in the study; they were randomly selected from a group of interested students. A research plan was established by the author and a participating teacher, who took responsibility for running the study, whilst the author took care of data collection. The plan was based on:

1. Introduction and training in using the digital output devices.

2. Students developed drawings and solutions with a pencil and then two different drawing tablets.

The teacher explained the plan to the students and showed them how to use the digital tablets. Then he conducted a drawing test for the students, based on the following:

1. Using a normal pencil on paper, they were asked to draw three dimensional drawings of a box, a cylinder, a small shelf and a house with a car in front of it.

2. They were then asked to draw a three dimensional drawing of a house with the initial digital pen tablets and computer.

3. Then students were then asked to draw their own design of a house with the Pegasus digital tablets.
Typically the tablets were connected to computers to enable the students to see their drawings and save them on the hard drive. Subsequently these drawings were compared with those produced when the students used the Pegasus digital tablets to draw solutions. Part of the students used the Pegasus tablets before the initial tablets. This was done as there would be maturation effects if the same exercises were repeated with the new pen.

\section{Data Collection and Analysis}

The study was founded on an interpretive paradigm: the data was qualitative and the analysis based on grounded theory principles. This focused on understanding the use of digital drawing tablets in a school context, and was done by describing and interpreting human communications, learning performance and use of the drawing technology.

The author used various data instruments, in order to enable triangulation and increase validity. The data instruments were selected to enable triangulation and reliability; these were the interview with the teacher, interview with individual students, students' drawings from tests in the classroom and video recording in the classroom. In order to analyse the data, the qualitative and inductive methodology, as developed by Glaser and Strauss (1967), was used. The specific instruments are listed against the research questions in the Table 1.

Table 1. Data collection methods used in the study

\begin{tabular}{|ll|}
\hline 1. & Observation, \\
\hline 2. & Students' drawings from tests in the classroom \\
\hline 3. & Interviews with the teacher \\
\hline 4. & Interviews with individual students \\
\hline 5. & Screen captured videos \\
\hline 6. & Video recordings in the classroom \\
\hline
\end{tabular}

The data was treated as follows:

1. Raw data collected and translated

2. Raw data summarised

3. Summaries analysed and classified into categories

4. Findings discussed and conclusions written for each data source

5. All the categories from the three data sources brought together and classified 
6. Overall discussion written in the light of the literature and triangulation established

7. Conclusions drawn relating to the research questions.

In addition, an assessment form was set up for the drawing test in collaboration with two English Design and Technology teachers at Loughborough University that gave their comments and piloted it. Subsequently it was upgraded and carried out by four postgraduate students at the same University.

The main aim was to examine the students' ability to draw with different methods and also to mark the quality of the drawings. It also gave the author data to enable the author to describe the differences between the three drawings methods used by the students and the quality of the drawings.

The author gave each postgraduate 15 minutes to finish the assessment and they had to complete it alone and without being able to discuss it with someone else. None of the students had seen the drawings before or the drawing equipment. Before each student began the author explained the test but without describing how it was done or showing the equipment. This was done to avoid the students would be affected by the author opinion or any other person.

\section{Summary of Findings of Data from the Drawing Tests}

In order to estimate the difference between the three different methods of drawing the author set up a table for accuracy, 3D drawing skill, detailed drawing and expression. He asked the four post graduate students to compare the eight students output and give them grades from 1-10 for the work. The average grade is shown in the table below as answers to the questions. Consequently, this is used to interpret tests:

- Accuracy: How accurate are the drawings (lines)? Grade 1-10.

- 3D skill: How well did the student represent the 3D? Grade 1-10.

- Detailed drawing: How detailed are the drawings? Grade 1-10.

- Clarity: How easy is it to understand the drawings? Grade 1-10

- Realistic: How actual are the drawings? Grade 1-10.

Table 2 below shows the summary of the assessment and can be further visualized on Figure 3. Because the assessment were just carried out by four postgraduates' the author use the total sum of the assessment instead of describing the differences' between their

Table 2. The table shows assessments of the different drawings and the outcome of the four tests

\begin{tabular}{|l|l|l|l|l|l|l|l|l|l|l|l|l|l|l|l|l|}
\hline & 3D skill & \multicolumn{3}{l|}{ Detailed } & \multicolumn{3}{l|}{ Accurity } & \multicolumn{2}{l|}{ Realistic } \\
\hline N1 & 47 & 31 & 30 & 38 & 43 & 36 & 39 & 42 & 30 & 43 & 39 & 52 & 42 & 35 & 35 \\
\hline N2 & 51 & 35 & 27 & 49 & 29 & 28 & 51 & 37 & 23 & 46 & 30 & 22 & 46 & 25 & 20 \\
\hline N3 & 37 & 29 & 29 & 41 & 33 & 38 & 39 & 37 & 35 & 41 & 30 & 32 & 40 & 32 & 36 \\
\hline N4 & 33 & 18 & 18 & 28 & 24 & 25 & 33 & 22 & 14 & 28 & 21 & 21 & 30 & 17 & 15 \\
\hline Sum & 168 & 113 & 104 & 156 & 129 & 127 & 162 & 138 & 102 & 158 & 120 & 127 & 158 & 109 & 106 \\
\hline
\end{tabular}

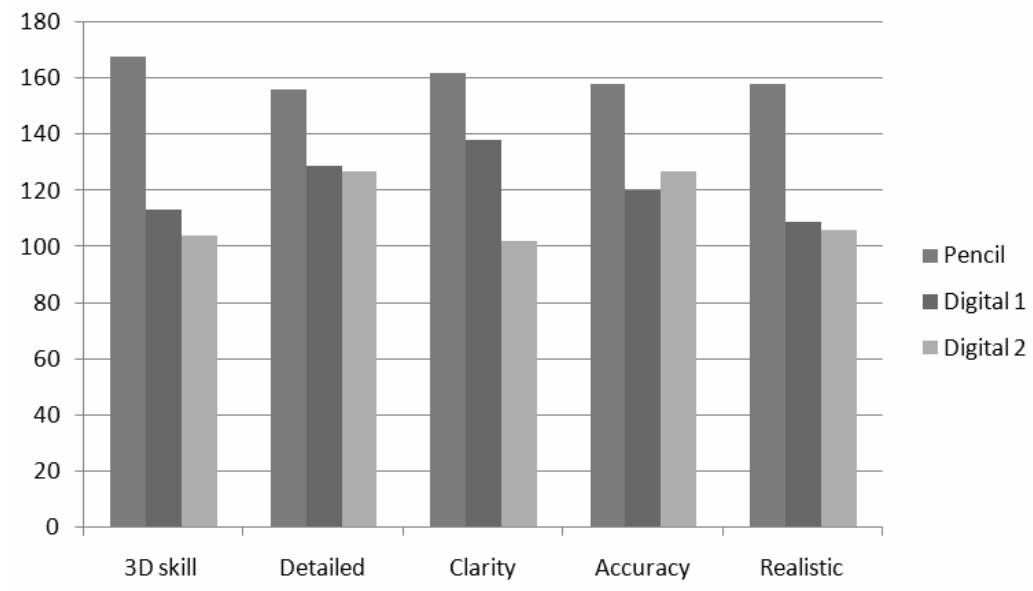

Figure 5. Shows the outcome of the assessment of the images 
works. More assessments' would have enabled such examination.

In addition each postgraduate student was asked to describe shortly the main difference between the three drawing methods? Their answers are summarized below:

Postgraduate one: The students' skill looks more important to me then the media they used to draw. More able students make better drawings, even by hand. The digital pens seem to be more difficult to use, then normal pencils. The third method (digital pen two) seems to be more accurate, but the 3D shapes were badly represented. The clarity of the drawings was more evident in a pencil.

Postgraduate two: Normal pencil drawings were clearer, more detailed and more realistic than drawings made by digital tablets. The 3D skills diminished when digital tablets were used.

Postgraduate three: Drawing with digital pen appeared to be a natural and good way of representing students' 3D skill and the drawings were detailed. Using the first digital pens affected the accuracy of the drawing. Drawing with the second digital pen tablets helped to make the drawings more detailed but 3D skills were not well represented.

Postgraduate four: The students were generally better in drawing with a pencil. The digital pen tablet one was better than the digital pen tablet two.

The analyzing of the assessments lead to the following outcome:

- It is better to use a pencil then digital pen tablets to draw;

- Students are generally better in drawing with a pencil then digital pen tablets,

- Initial digital pen tablets supported better drawings than the Pegasus tablets; except in accuracy;

- The digital pen tablet one was better than the digital pen tablet two.

- Students' skills are more important than the media.

\section{Discussion}

Effective drawing equipment and the CAD program were important in enabling students' work and training appeared to improve their skills. Nevertheless, students were able to learn the use of different tools through experience, without specific training. Their drawings became more accurate during the courses as a result of their growing experience and the use of more advanced drawing tablets. However, simple drawing tests showed that the students had to be taught to use the CAD program when digital pen tablets were used and when they formulated three- dimensional drawings. It was also noted that their skills improved during the drawing tests, probably because they were effectively undergoing informal training. This highlighted how drawing skills are more important than the media employed to draw with. Three different drawing tools and the CAD software were tested:

1. A normal pencil on paper,

2. Initial digital pens with the Paint software,

3. Wireless digital Pegasus pens, which were also, ink pens with specific software.

Tests showed that the students were better at using pencils than the digital pen tablets. However, they worked faster with the digital pen tablets and their drawing improved. Observations indicated that the initial digital drawing tablets were not flexible enough and slowed down work; they presented limitations in that a pen was used on the tablet, but the mark only appeared on the screen. However, the designs appeared to be more advanced than those created with the Pegasus tablets, except in terms of accuracy.

The Pegasus tablets were closest to the experience of drawing with a pen and were most accurate. Nevertheless, the video data indicated that better drawing tablets augmented students' idea generation. Students' drawings when using digital input devices were generally inaccurate, but demonstrated basic solutions to identified problem-needs and were therefore usable. However, Plimmer's (2008) research on digital pen input devices showed that the basic usability of pen-based input was lower than desired. He thus concluded that further research was required, in terms of the hardware, operating system support, recognition engines and design. This difference can be explained by the age of participants: in this research, the students were 12 years old, while, in Plummer's research, they were adult designers, with higher requirements.

In his research, van der Lugt (2005) categorized sketches according to the design 
progression they represented. He examined them as a mechanism for reinterpretation of an individual designer's ideas and found out that sketching is a way of stimulating innovative thoughts (van der Lugt, 2005). In the study, the teacher noted how limited drawing skills were a drawback, in terms of students' idea generation. He therefore offered to teach them formally, but the students asserted that they knew how to use the digital pens and the CAD programme (such instruction would most likely have improved the students work, both in terms of quality and productivity.

\section{Conclusion}

Drawing was identified as an important tool for ideation during the research, as it enabled students to record, communicate and develop solutions (van der Lugt, 2005; Purcell \& Gero, 1998; Ferguson, 1992; Chin \& Tan, 2007). The drawing, furthermore, supported individual work and the students' ability to work cooperatively inside the classroom, as indicated by Ferguson (1992).

Effective and useable digital drawing input devices and the CAD software were important in enabling students to draw and manipulate images. However, the different input devices gave lower quality graphical outcomes than drawing with a pencil, as reported by Plimmer (2008).

Students were very self-confident in their ability to learn to use these devices and it appeared they were able to learn to use them to a reasonable standard, without specific training. Nevertheless, training and experience were identified as important, if students are to attain a higher standard of drawing (Vlach, 2008; Cheng \& Lane-Cumming, 2004; Ning et al., 2004; Blackwell et al., 2008).

The students' drawings became more accurate as a result of more advanced drawing tablets. The Pegasus digital pen on paper was the most accurate of the drawing devices employed in the case studies, as it placed the image in the same place as the pen and emulated drawing on paper (in that students followed the marks made by the pen nib, rather than looking separately at the screen). Students' drawings were relatively inaccurate; this was partly due to limited input devices, but their drawings were good enough to demonstrate basic solutions (see also Plimmer's research, 2008).

\section{REFERENCES}

1. MARKS, A., Audio Haptics for Visually Impaired Information Technology. Axistive, 2007, Retrieved (5. April 2012) from http://www.axistive.com/audiohaptics-for-visually-impaired-informationtechnology.html.

2. BLACKWELL, A. F., L. CHURCH, B. PLIMMER, D. GRAY, Formality in Sketches and Visual Representation: Some Informal Reflections. In B. Plimmer and T. Hammond (Eds). Sketch Tools for Diagramming, workshop at VL/HCC 2008, pp. 11-18.

3. Britannica, Gray, Elisha. Retrieved (5. April 2012) from http://www.britannica.com/EBchecked/topi c/242617/Elisha-Gray.

4. CHENG, Y. N., S. LANE-CUMMING, Teaching with Digital Sketches. University of Oregon, Pre-publication draft for the Design Communication Association's 11th Biennial Conference, January 9-10. California Polytechnical University, San Luis Obispo, California, 2004.

5. CHIN, C. S., J. TAN, Use of Sketch Book Pro with Tablet PC (Tab-Sketch ${ }^{\mathrm{TM}}$ ) as a Design-thinking Tool in the Teaching and Learning of Design and Technology. In: Norman, E.W.L. and Spendlove, D. (eds.). The Design and Technology Association International Research Conference 2007, University of Wolverhampton, Telford Campus, 4, 5, 6 July. Wellesbourne: The Design and Technology Association, 2007, pp. 11-20.

6. COPPOCK, J. T. D. W. RHIND, The History of GIS. In Maguire D.J., Goodchild M.F., and Rhind D.W. (editors) Geographical Information Systems: Principles and Applications, Vol. 1, No. 1, 1991, pp. 21-43.

7. DAVIS, M. T. E. The RAND Tablet: A Man-Machine Graphical Communication Device. ARPA 1964. Retrieved 24 March 2012 from http://www.rand.org/pubs/research_memor anda/2005/RM4122.pdf.

8. DIMOND, T. L., Devices for Reading Handwritten Characters, Proceedings of 
Eastern Joint Computer Conference, held in December 9-13, 1957: Computers with deadlines to meet, ACM. Washington, D.C., pp. 232-237.

9. FERGUSON, E. S. Engineering and the Mind's Eye. Cambridge: MIT, 1992.

10. FISCHER, S. R., A History of Writing. Reaktion Books, 2001.

11. GLASER, B. G. A. L. STRAUSS, The Discovery of Grounded Theory: Strategies for Qualitative Research. New York: Aldine Publishing Company, 1967.

12. GOLDSCHMIDT, G., The Backtalk of Self-generated Sketches, In Visual and Spatial Reasoning in Design. Cambridge, USA. 1999, pp. 163-184.

13. http://www.britannica.com/EBchecked/topi c/242617/Elisha-Gray

14. MCINNERNEY, C., Knowledge Management and the Dynamic Nature of Knowledge, Journal of the American Society for Information Science and Technology, Vol. 53, No.12, 2002, pp. 1009-1018.

15. NING, H., R. J. WILLIAMS, H. A. SLOCUM, A. SANCHEZ, Inkboard Tablet PC Enabled Design-Oriented Learning, 7th International Conference on Computers and Advanced Technology in Education, Hawaii, 2004.

16. PAGE, T., Prospects for the Design of Electronic Products in Second Life. Journal of Studies in Informatics and Control, Vol. 20, No. 3, 2011, pp. 293-303. ISSN 1220-1766.
17. PAGE, T., G. THORSTEINSSON, A. NICULESCU, Management of Knowledge in a Problem Based Learning Environment, Studies in Informatics and Control, Vol. 18, No. 3, 2009, pp. 225-262. ISSN 1220-1766.

18. PLIMMER, B. Experiences with Digital Pen, Keyboard and Mouse Usability. Multimodal User Interfaces, Vol. 2, No. 1, 2008, pp. 183-186.

19. PURCELL, A. T., J. S. GERO, Drawings and the Design Process. Design Studies, Vol. 19, No. 4, 1998, pp. 389-430.

20. SIMON, H. A. The Sciences of The Artificial (2nd ed.). Cambridge, MA: The MIT Press, 1981.

21. The Oxford English Dictionary Online (2012). Retrieved (5. April, 2012) from http://www.oed.com/

22. ULLMAN, D. G. The Mechanical Design Process. Mc Graw Hill, 4th edition. 2009

23. Van der LUGT, R. How Sketching Can Affect the Idea Generation Process Is Design Group Meetings. Design Studies, Vol. 26, No. 3, 2005, pp.101-122.

24. VLACH, H. A., The Effects of Observation Coaching on Children's Graphic Representations. Early Childhood Research \& Practice (ECRP), Vol. 10, No. 1. Illinois: Clearinghouse on Early Education and Parenting (CEEP). 